\title{
EVALUATION OF INFRASTRUCTURE PROJECTS BY A DECISION MODEL BASED ON RPR, MABAC, AND WASPAS METHODS WITH INTERVAL-VALUED INTUITIONISTIC FUZZY SETS
}

\author{
Sina SALIMIAN ${ }^{1}$, Seyed Meysam MOUSAVI ${ }^{1,}$, Jurgita ANTUCHEVIČIENĖ (10) ${ }^{2}$ \\ ${ }^{1}$ Department of Industrial Engineering, Shahed University, Tehran, Iran \\ ${ }^{2}$ Department of Construction Management and Real Estate, Vilnius Gediminas Technical University, Vilnius, Lithuania
}

Received 23 September 2021; accepted 31 January 2022

\begin{abstract}
Infrastructure projects (IPs) face numerous challenges to reach the predefined aims over their life-cycle. There are many difficulties in projects because of the variety of elements in project's tendency and the dependency of the project on mainly national factors. Due to these difficulties and their practices, the projects meet with uncertainty. In this paper, an interval-valued intuitionistic fuzzy set (IVIFS) is used at identifying ambiguity in IPs. Also, a new multi-criteria decision-making (MCDM) model is presented to evaluate and select the suitable alternative in IPs. Hence, a new IVIF-relative preference alternative-multi-attributive border approximation area comparison (IVIF-RPR-MABAC), and IVIF-weighted aggregated sum product assessment (IVIF-WASPAS) are proposed in order to obtain the weights of decision makers (DMs) and criteria, and a new IVIF-RPR-MABAC method is proposed to rank the alternatives. In this paper, a combination of the three mentioned approaches creates proposed new hybrid model to evaluate the main factors and the projects. Furthermore, a real case study is applied from the literature to validate the efficiency and performance of the proposed model. Afterward, a comparative analysis is presented to validate the proposed approach by comparing the hybrid proposed model with two IVIF-TOPSIS and IVIF-extended-VIKOR methods. The final results confirm the efficiency of the proposed model in ranking the main alternatives of an MCDM problem. Moreover, the sensitivity analysis is reported to determine the affection of parameters on the final weighting and ranking outcomes.
\end{abstract}

Keywords: infrastructure projects, multi-criteria decision-making (MCDM), interval-valued intuitionistic fuzzy sets (IVIFSs), relative preference alternative (RPR) method, multi-attributive border approximation area comparison (MABAC) method, weighted aggregated sum product assessment (WASPAS) method.

\section{Introduction}

Infrastructure projects (IPs) display an essential practice in construction conditions that links constructing and manufacturing projects to energy, water, and other topics to each other. The kinds of projection may develop distinctive scheming challenges because they may include the right to cross over another property adjustments, involve more basement construction than building or manufacturing projections, and may need more connection with the universe than other kinds of construction projects. An IP can be described as a megaproject, which comprises forwarding, transferring, distributing, collecting, or other abilities that support patronage or interaction of products, ministrations, or population (Bingham \& Gibson, 2017); especially, an IP is horizontal in characters and practices as a vector that joins constructing and manufacturing depots within the manufacturing state. IPs may transmit persons, such as freeways, railways, and tunnels; they may extend liquids, such as tube lines, open channels, and pumping stations; or they may account for energy, such as transferring lines, electrical towers, and wayside (Construction Industry Institute, 2010).

The increasing world population rate and the need for growth IPs like transportation are straining existing and extending the requirement for megaprojects. Financial resources are rare and so should be allocated effectively. Correctly assessing transportation infrastructure in costbenefit analysis will provide the most effective allocation of resources and do extra with fewer devices. Nevertheless, the elaborative and particular nature of IPs should be thoroughly managed (Taillandier et al., 2015). Likewise projects want detailed appraisement within the planning

*Corresponding author. E-mail: sm.mousavi@shahed.ac.ir 
step for selection, comparison, and evaluation of proper projects alternatives. In project evaluation and selection process, which is classified as a strategic decision-making procedure, the decision maker (DM) is required to find a number of the most appropriate projects although considering the result of projects (Pires et al., 2018). Accordingly, there are various multi-criteria decision-making (MCDM) methods for assessing and selecting processes in IPs. Hence, there is no well-described approach that could be followed the decision-assisting process (Yazdani et al., 2011). The selection and evaluation of IP methodology are still under paper. The major case is to approximate and appraise a collection of options in kinds of indexes and inconsistent criteria (Mulliner et al., 2016). There are diverse measures for each index and criterion (Egilmez et al., 2016). One of the criticisms of MCDM approaches is that mixed methods can outcome multiple results when practical to the same subject. The DMs regard a suitable decision, which is nearest to the ideal, and options are assessed accordance with all demonstrate criteria (Chitsaz \& Banihabib, 2015). It is essential to compare the MCDM approach for evaluation aims with a sensitivity analysis of the input information. It is also significant to experiment with the ability of different approaches by a particular kind of decision problem (Gan \& Hill, 2009).

One of the other elements is related to an increasing extensive amount of ambiguity and uncertainty in most IPs, which usually occurs for evaluation and selection of suitable projects in complex decision-making problems by considering transferring process (Arshad et al., 2021). Accordingly, the fuzzy set (FS) is presented to reduce the probability lack of information by utilizing fuzzy numbers instead of numerical amounts to demonstrate the DMs' intuitive preferences. Still, it cannot reflect a well-known mental fact that the linguistic value is not consistently recognized with the rational term (Wu et al., 2014). In this regard, from the various higher levels of FSs, intuitionistic fuzzy sets (IFSs) proposed by Atanassov (1986) have been introduced to be extremely useful to cope with vagueness. The issue of IFSs is an extension of the FSs. The subject of vague sets proposed by Gau and Buehrer (1993) is another extension of FSs. However, Bustince and Burillo (1996) introduced that the notion of a vague set is the same as the IFSs. Due to the incrementing elaboration of the social and economic environments, the shortage of information about the problem, and expert's ability relevant to the information process, sometimes, an expert is hard to prioritize describing options with regard to criteria precisely but can give a value range. In this respect, for assessing an index, DM may be more comfortable to represent the value of criterion with satisfactory and dissatisfactory degrees by utilizing an interval value, respectively (Hashemi et al., 2013; Salimian \& Mousavi, 2021). This point can be applied in the IFs environment, which creates the intervalvalued intuitionistic fuzzy set (IVIFS) concept. The main advantage of IVIFSs is related to the capability of IVIFS to manage a non-membership degree in addition to the membership degree of fuzzy values that is a favored point of this method over traditional fuzzy sets (Davoudabadi et al., 2019, 2020). Furthermore, IVIFS utilizes the interval values for determining the degrees instead of using a crisp value. Also, vague information can be managed adequately by employing IVIFSs in comparison with IFSs. By extending IFSs to IVIFSs, controlling uncertain and vague information becomes more successful due to the particular that the ambiguous, membership and non-membership degrees are represented as ranges of values instead of actual values (Davoudabadi et al., 2021).

For this reason, Gürbüz et al. (2012) presented an integrated MCDM method to select the ERP problem with a conflict criterion. Zhang et al. (2019) proposed the private-sector partner selection for the public-private partnership (3P) charging electric vehicles infrastructure problem. The study used the extended Vlse Kriterijumska Optimizacija Kompromisno Resenje (VIKOR) method under the IFS condition. Turskis et al. (2019) generated the MCDM problem in the runway airport project. This paper applied the group decision-making (GDM) process to take an appropriate decision and select an effective alternative. Wang (2015) proposed weighting criteria approach by combining fuzzy quality function deployment with relative preference relation (RPR). The advantage of the RPR is that uncertainties of fuzzy values are kept during the ranking and weighting process, and another is related to control fuzzy pairwise comparisons by preference relation that is complex. Furthermore, the multi-attributive border approximation area comparisons (MABAC) methid has been proposed by Pamučar and Ćirović (2015) and categorized as a multi-attributes decision-making (MADM) approach to compute the criteria weights. The advantages of MABAC method are the simple calculation and durability in solution and the potential amounts of advantages and losses which to be considered in such a way that the final drawback can be extensive (Roy et al., 2016). Zavadskas et al. (2012) proposed the weighted aggregated sum product assessment (WASPAS) approach to evaluate the decision process in the complex problem. In addition, Chakraborty and Zavadskas (2014) introduced WASPAS method to compute the manufacturing decisionmaking process. Karsak and Dursun (2015) proposed the combination fuzzy MCDM approach to select and assess the supplier. Xue et al. (2016b) presented a combination linguistic MCDM approach to assess and select with incomplete weight data. Stević et al. (2018) proposed the MCDM method based on the WASPAS approach to evaluate location of the roundabout construction. The proposed WASPAS approach was created based on a new rough hamy aggregator. Navarro et al. (2020) introduced the sustainable lifecycle of the bridge construction project under MCDM technology. Baušys et al. (2020) focused on the residence plot for a family house in Vilnius using neutrosophic WASPAS method.

Brauers et al. (2008) proposed the MCDM approach to assess the road design problem. Fouladgar et al. (2012) introduced the combination AHP and complex proportional assessment (COPRAS) under fuzzy environments to select 
the maintenance strategy. Turskis et al. (2015) presented integrated fuzzy AHP and WASPAS approach to select the construction site. Keshavarz Ghorabaee et al. (2016) generated the development WASPAS method to select the green supplier in type-2 fuzzy set conditions. Zavadskas et al. (2015) evaluated the sustainable alternative site of the waste burn factory with WASPAS method under netroustophic set. Zavadskas et al. (2016) introduced the WASPAS approach to select the optimal indoor environment. Yazdani et al. (2011) evaluated the supplier selection with QFDMCDM structure in green environments. Mohagheghi et al. (2019) proposed a sustainable infrastructure selection multi-criteria group decision making (MCGDM) problem with MORAS method under interval type-2 fuzzy conditions. Mazher et al. (2018) introduced fuzzy integral-based risk-evaluation method for 3P-IPs. Stević et al. (2020) proposed the measurement of alternatives and ranking according to the compromise solution (MARCOS) approach to select the sustainable supplier in healthcare industry. Ranganath et al. (2020) proposed an application of fuzzy technique for order of preference by similarity to ideal solution (TOPSIS) approach for risk assessment in extended and executed of solar park in India. Su and Li (2021) introduced project appropriation approach decision-making with Spearman rank similarity coefficient under uncertain situations. Bapat et al. (2021) proposed an application of combined fuzzy FCM-BIM-IoT for sustainable material choice and energy management of metro rail service box project in western India. Banihashemi et al. (2021) proposed an integrated fuzzy SWARA-TOPSIS method to evaluate the trade-off among time-cost-quality in construction project scheduling problems.

This paper proposes a new hybrid weighting and ranking model that includes IVIF-RPR-MABAC, IVIF-WASPAS, and new IVIF-RPR-MABAC approaches for solving the evaluation and selection problems of IPs. Therefore, integrating the RPR and MABAC methods is utilized to obtain the DMs weights. Also, the criteria weights are computed based on the WASPAS method. Eventually, a new hybrid assessment model based on RPR and MABAC methods is presented to compute the ranking of main alternatives for the IPs problems. Afterward, a case study is applied based on the literature to validate the performance of the introduced model, and this study compares the suggested method with two IVIF-TOPSIS and IVIFextended-VIKOR (IVIF-E-VIKOR) approaches. The main innovations of the paper are examined below:

- Proposing a new DM' weighting method based on an IVIF-RPR-MABAC approach. This method uses the average, negative and positive ideal solutions distances to compute the DMs' weights.

- Introducing a criterion weighting method based on a new version of the IVIF-WASPAS approach.

- Proposing a new ranking method based on the MABAC and RPR concepts under IVIF conditions.

- Applying a case study to validate the introduced decision model.
The remaining part of this paper is turned out as follows. The based formulation of IVIF method is reviewed in Section 1. In Section 2, the proposed soft computing model is introduced. In Section 3, an empirical example is generated based on the literature. Section 4 investigates the sensitivity analysis. Eventually, the last section develops the conclusion and the future research suggestion.

\section{Preliminary}

This section describes the basic formulations of IVIFS and RPR method. These descriptions are shown below:

Definition 1. (Atanassov \& Gargov, 1989). Let $Y=\left\{y_{1}, y_{2}, \ldots, y_{n}\right\}$ be a universe. An IVIFS $\tilde{P}$ in $Y$ is defined from Eq. (1).

$$
\tilde{P}=\left\{y_{i}, \mu_{\tilde{P}}\left(u_{i}\right), v_{\tilde{P}}\left(u_{i}\right) \mid y_{i} \in Y\right\},
$$

where $\mu_{\tilde{P}}\left(y_{i}\right)=\left[\mu_{\tilde{P}}^{l}\left(y_{i}\right), \mu_{\tilde{P}}^{u}\left(y_{i}\right)\right], v_{\tilde{P}}\left(y_{i}\right)=\left[v_{\tilde{P}}^{l}\left(y_{i}\right), v_{\tilde{p}}^{u}\left(y_{i}\right)\right]$ and $\mu_{\tilde{P}}\left(y_{i}\right), v_{\tilde{P}}\left(y_{i}\right) \in[0,1]$. In these formulations, $\mu_{\tilde{P}}^{l}\left(y_{i}\right)$ is the infimum of the $\mu_{\tilde{P}}\left(y_{i}\right)$ and $\mu_{\tilde{P}}^{u}\left(y_{i}\right)$ is the supremum of the $\mu_{\tilde{P}}\left(y_{i}\right)$. Furthermore, this situation is done for $v_{\tilde{P}}\left(y_{i}\right)$, simultaneously.

$$
\begin{aligned}
& \mu_{\tilde{P}}^{u}\left(y_{i}\right)+v_{\tilde{P}}^{u}\left(y_{i}\right) \leq 1 \quad \forall y_{i} \in Y ; \\
& \pi_{\tilde{P}}\left(y_{i}\right)=\left[\pi_{\tilde{P}}^{l}\left(y_{i}\right), \pi_{\tilde{P}}^{u}\left(y_{i}\right)\right],
\end{aligned}
$$

where $\pi_{\tilde{P}}^{l}\left(y_{i}\right)=1-\mu_{\tilde{P}}^{u}\left(y_{i}\right)-v_{\tilde{P}}^{u}\left(y_{i}\right)$ and $\pi_{\tilde{P}}^{u}\left(y_{i}\right)=1-\mu_{\tilde{P}}^{l}\left(y_{i}\right)$ $v_{\tilde{P}}^{l}\left(y_{i}\right)$ for $y_{i} \in Y$. Hence, if $\mu_{\tilde{P}}\left(y_{i}\right)=\mu_{\tilde{P}}^{u}\left(y_{i}\right)=\mu_{\tilde{P}}^{l}\left(y_{i}\right)$ and $v_{\tilde{P}}\left(y_{i}\right)=v_{\tilde{P}}^{u}\left(y_{i}\right)=v_{\tilde{P}}^{l}\left(y_{i}\right)$, IFS is created.

Definition 2. (Atanassov, 1999). Let

$\tilde{Q}_{1}=\left(\left[\mu_{\widetilde{Q_{1}}}^{l}, \mu_{\widetilde{Q_{1}}}^{u}\right],\left[v_{\widetilde{Q_{1}}}^{l}, v_{\mathrm{Q}_{1}}^{u}\right]\right), \tilde{Q}_{2}=\left(\left[\mu_{\widetilde{Q_{2}}}^{l}, \mu_{\mathrm{Q}_{2}}^{u}\right],\left[v \widetilde{Q_{2}}, v_{\mathrm{Q}_{2}}^{u}\right]\right)$, $\tilde{Q}=\left[\mu_{\tilde{Q}}^{l}, \mu_{\tilde{Q}}^{u}\right],\left[v_{\tilde{Q}}^{l}, v_{\tilde{Q}}^{u}\right]$. The major operations are dem-

onstrated with Eqs (4)-(7).

$$
\begin{aligned}
& \tilde{Q}_{1} \otimes \tilde{Q}_{2}=\left(\left[\mu_{\widetilde{Q_{1}}}^{l}+\mu_{\widetilde{Q_{2}}}^{l}-\mu_{\widetilde{Q_{1}}}^{l} \mu_{\widetilde{Q_{2}}}^{l}, \mu_{\widetilde{Q}_{1}}^{u}+\mu_{\widetilde{Q}_{2}}^{u}-\mu_{\widetilde{Q}_{1}}^{u} \mu_{\widetilde{Q}_{2}}^{u}\right]\right. \\
& \left.\left[v_{\widetilde{Q_{1}}}^{l} v_{\widetilde{Q_{2}}}^{l}, v \widetilde{Q_{1}} v_{\widetilde{Q_{2}}}^{u}\right]\right) ;
\end{aligned}
$$

$$
\tilde{Q}_{1} \otimes \tilde{Q}_{2}=\left(\left[\mu_{\widetilde{Q_{1}}}^{l} \mu_{\mathrm{Q}_{2}}^{l}, \mu{\widetilde{Q_{1}}}_{\mathrm{Q}_{2}}^{u} \mu_{\widetilde{u}}^{u}\right],\right.
$$$$
\left.\left[v v_{\mathrm{Q}_{1}}^{l}+v_{\widetilde{Q_{2}}}^{l}-v_{\widetilde{Q_{1}}}^{l} v_{\widetilde{Q_{2}}}^{l}, v_{\mathrm{Q}_{1}}^{u}+v_{\mathrm{Q}_{2}}^{u}-v_{\widetilde{Q_{1}}}^{u} v_{\mathrm{Q}_{2}}^{u}\right]\right) ;
$$

$$
\begin{aligned}
& E \tilde{Q}=\left(\left[1-\left(1-\mu_{\tilde{Q}}^{l}\right)^{E}, 1-\left(1-\mu_{\tilde{Q}}^{u}\right)^{E}\right],\left[v_{\tilde{Q}}^{l E}, v_{\tilde{Q}}^{u^{E}}\right]\right) ; \\
& \tilde{Q}^{E}=\left(\left[\mu_{\tilde{Q}}^{l^{E}}, \mu_{\tilde{Q}}^{u^{E}}\right]\left[1-\left(1-v_{\tilde{Q}}^{l}\right)^{E}, 1-\left(1-v_{\tilde{Q}}^{v}\right)^{E}\right]\right) .
\end{aligned}
$$


Definition 3. (Xue et al., 2016a). Euclidean distance is obtained from Eq. (8).

$\operatorname{Dis}\left(\tilde{Q}_{1}, \tilde{Q}_{2}\right)=$

$\sqrt{\frac{1}{4}\left(\left(\mu_{\widetilde{Q_{1}}}^{l}-\mu_{\widetilde{Q_{2}}}^{l}\right)^{2}+\left(\mu_{\widetilde{Q_{1}}}^{u}-\mu_{\widetilde{Q_{2}}}^{u}\right)^{2}+\left(v_{\widetilde{Q_{1}}}^{l}-v_{\widetilde{Q_{2}}}^{l}\right)^{2}+\left(v_{\widetilde{Q_{1}}}^{u}-v_{\widetilde{Q_{2}}}^{u}\right)^{2}\right)}$

Definition 4. (Büyüközkan \& Göçer, 2018). The normalized decision matrix is calculated from Eqs (9)-(12).

$$
\begin{aligned}
& \mu_{i j}^{l}=\frac{\tilde{\mu}_{i j}^{l}}{\sqrt{\sum_{i=1}^{r}\left(\tilde{\mu}_{i j}^{l^{2}}+\tilde{\mu}_{i j}^{l^{2}}\right)}} ; \\
& \mu_{i j}^{u}=\frac{\tilde{\mu}_{i j}^{u}}{\sqrt{\sum_{i=1}^{r}\left(\tilde{\mu}_{i j}^{u}+\tilde{\mu}_{i j}^{u}\right)}} ; \\
& v_{i j}^{l}=\frac{\tilde{v}_{i j}^{l}}{\sqrt{\sum_{i=1}^{r}\left(\tilde{v}_{i j}^{l^{2}}+\tilde{v}_{i j}^{l^{2}}\right)}} ; \\
& v_{i j}^{u}=\frac{\tilde{v}_{i j}^{u}}{\sqrt{\sum_{i=1}^{r}\left(\tilde{v}_{i j}^{u^{2}}+\tilde{v}_{i j}^{u^{2}}\right)}} .
\end{aligned}
$$

Definition 5. (Xu \& Jian, 2007). The interval-valued intuitionistic fuzzy hybrid averaging (IVIFHA) approach is computed from Eq. (13).

$$
\begin{aligned}
& \operatorname{IVIFHA}_{w}=\left(\left[1-\prod_{j=1}^{h}\left(1-\mu_{\delta^{j}}^{u}\right)^{w^{j}}, 1-\prod_{j=1}^{h}\left(1-\mu_{\delta^{j}}^{l}\right)^{w^{j}}\right],\right. \\
& \left.\left[\prod_{j=1}^{h}\left(v_{\delta^{j}}^{u}\right)^{w^{j}}, \prod_{j=1}^{h}\left(v_{\delta^{j}}^{l}\right)^{w^{j}}\right]\right) .
\end{aligned}
$$

Definition 6. (Jia et al., 2019). The approximation area matrix is computed from Eq. (14).

$$
\begin{aligned}
& P_{i}=\left(\left[\prod_{j=1}^{h}\left(\mu_{i j}^{l}\right)^{(1 / h)}, \prod_{j=1}^{h}\left(\mu_{i j}^{u}\right)^{(1 / h)}\right],\right. \\
& \left.\left[1-\prod_{j=1}^{h}\left(1-v_{i j}^{l}\right)^{(1 / h)}, 1-\prod_{j=1}^{h}\left(1-v_{i j}^{u}\right)^{(1 / h)}\right]\right) .
\end{aligned}
$$

\section{Proposed soft computing model}

This section determines a new model for decision-making process under IVIF conditions that is used in IP evaluation and selection problems. The weights of the DMs are computed from the new prescription of the combination RPR and MABAC methods, and the criteria weights are obtained from the WASPAS approach under IVIF situations. Also, a new ranking method is proposed based on the latest version of MABAC and RPR approaches under the IVIF state. In the model, some concepts based on the recent papers are used for MCDM problems (i.e., Yue, 2012; Zavadskas et al., 2014; Mishra \& Rani, 2018; Dorfeshan \& Mousavi, 2020).

1. Creating a decision-making matrix based on $e$ expert opinions $\left(D=\left\{D_{1}, D_{2}, \ldots, D_{e}\right\}\right)$.

This matrix is related to the DMs' judgments between criteria $i=\left\{R_{1}, R_{2}, \ldots \ldots, R_{r}\right\}$ and the alternatives $j=\left\{M_{1}, M_{2}, \ldots \ldots, M_{h}\right\}$. Also, decision-making matrix $\left(\varnothing_{e}\right)$ is determined below.

$$
\varnothing_{e}=\left[\varnothing^{e}\right]_{i j}=\left[\begin{array}{ccc}
\tilde{\varnothing}_{11}^{e} & \cdots & \tilde{\varnothing}_{1 h}^{e} \\
\vdots & \ddots & \vdots \\
\tilde{\varnothing}_{r 1}^{e} & \cdots & \tilde{\varnothing}_{r h}^{e}
\end{array}\right] \text {, }
$$

where, $i \subseteq\{1,2, \ldots, r\}$ and $j \subseteq\{1,2, \ldots, h\}$ depict the quantity of the criteria and the alternatives. Furthermore, $E \subseteq\{1,2, \ldots, e\}$ generates the quantity by the DMs.

2. Computing normalized decision matrix based on Definition 4.

This is determined in Eqs (16) and (17).

$$
\begin{aligned}
& \eta_{i j}^{e}=\left[\begin{array}{ccc}
\tilde{\eta}_{11}^{e} & \cdots & \tilde{\eta}_{1 h}^{e} \\
\vdots & \ddots & \vdots \\
\tilde{\eta}_{r 1}^{e} & \cdots & \tilde{\eta}_{r h}^{e}
\end{array}\right] ; \\
& \tilde{\eta}_{i j}^{e}=\left(\begin{array}{l}
{\left[\frac{\tilde{\mu}_{i j}^{e l}}{\sqrt{\sum_{j=1}^{h}\left(\tilde{\mu}_{i j}^{l^{2}}+\tilde{\mu}_{i j}^{e l}\right)}}, \frac{\tilde{\mu}_{i j}^{e u}}{\sqrt{\sum_{j=1}^{h}\left(\tilde{\mu}_{i j}^{e u^{2}}+\tilde{\mu}_{i j}^{e u^{2}}\right)}}\right]} \\
{\left[\frac{\tilde{v}_{i j}^{e l}}{\sqrt{\sum_{j=1}^{h}\left(\tilde{v}_{i j}^{e{ }^{2}}+\tilde{v}_{i j}^{e{ }^{2}}\right)}}, \frac{\tilde{v}_{i j}^{e u}}{\sqrt{\sum_{j=1}^{h}\left(\tilde{v}_{i j}^{e{ }^{2}}+\tilde{v}_{i j}^{e u^{2}}\right)}}\right]}
\end{array}\right)
\end{aligned}
$$

3. Computing the weights of the experts by introducing IVIF-RPR-based MABAC approach.

Meanwhile, in this study, Yue (2012) method is presented to show DMs weights based on the closeness to the average ideal solution, and the expert with higher closeness gets the high weight degree. In this regard, a new weighting DMs approach is computed based on utilizing a closeness to the average ideal solution with the following sub-steps:

3.1. Obtaining the border approximation area matrix based on Definition 6 with Eq. (18).

$$
\begin{gathered}
\overline{\tilde{\xi}}_{i j}=\left[\begin{array}{ccc}
\overline{\tilde{\xi}}_{11} & \cdots & \overline{\tilde{\xi}}_{1 h} \\
\vdots & \ddots & \vdots \\
\overline{\tilde{\xi}}_{r 1} & \cdots & \overline{\tilde{\xi}}_{r h}
\end{array}\right] ; \\
\overline{\tilde{\xi}}_{r h}=\left(\left[\prod_{e=1}^{E}\left(\mu_{r h}^{e l}\right)^{(1 / e)}, \prod_{e=1}^{E}\left(\mu_{r h}^{e u}\right)^{(1 / e)}\right],\right. \\
\left.\left[1-\prod_{e=1}^{E}\left(1-v_{r h}^{e l}\right)^{(1 / e)}, 1-\prod_{e=1}^{E}\left(1-v_{r h}^{e u}\right)^{(1 / e)}\right]\right) .
\end{gathered}
$$


3.2. Computing the IVIF-RPR based on the border approximation area matrix with Eqs (20)-(26).

In this formulation, $\Delta_{P^{*}}\left(\tilde{\eta}_{r h}^{e}, \overline{\tilde{\xi}}_{i j}\right)$ determines a preference degree of the $\tilde{\eta}$ over $\tilde{\xi}$. Also, $\Delta_{P}$ is a membership degree of fuzzy preference relation $P$.

$\partial_{e}=\sum_{i=1}^{r} \sum_{j=1}^{h} \Delta_{P^{*}}\left(\tilde{\eta}_{i j}^{e}, \overline{\tilde{\xi}}_{i j}\right)=\frac{1}{2}\left[\Delta_{P^{*}}\left(\tilde{\eta}_{i j}^{l e}, \overline{\tilde{\xi}}_{i j}^{l}\right)+\Delta_{P^{*}}\left(\tilde{\eta}_{i j}^{u e}, \overline{\tilde{\xi}}_{i j}^{u}\right)\right]=$
$\left(\begin{array}{l}\frac{1}{2}\left[\frac{1}{2}\left(\frac{\sum_{i=1}^{r} \sum_{j=1}^{h}\left(\mu_{i j}^{l e}-\bar{\mu}_{i j}^{l}\right)}{2\left\|T_{\xi}^{\mu l}\right\|}+1\right)+\frac{1}{2}\left(\frac{\sum_{i=1}^{r} \sum_{j=1}^{h}\left(\mu_{i j}^{u e}-\bar{\mu}_{i j}^{u}\right)}{2\left\|T_{\xi}^{\mu u}\right\|}+1\right)\right], \\ \frac{1}{2}\left[\frac{1}{2}\left(\frac{\sum_{i=1}^{r} \sum_{j=1}^{h}\left(v_{i j}^{l e}-\bar{v}_{i j}^{l}\right)}{2\left\|T_{\xi}^{v l}\right\|}+1\right)+\frac{1}{2}\left(\frac{\sum_{i=1}^{r} \sum_{j=1}^{h}\left(v_{i j}^{u e}-\bar{v}_{i j}^{u}\right)}{2\left\|T_{\xi}^{v u}\right\|}+1\right)\right]\end{array} ;\right.$

$\left\|T_{\xi}^{\mu u}\right\|=\left\{\begin{array}{c}\frac{\sum_{i=1}^{r} \sum_{j=1}^{h}\left(t_{i j}^{+\mu u}-t_{i j}^{-\mu u}\right)}{2} \quad \text { if } t_{i j}^{+\mu u} \geq t_{i j}^{-\mu u} \\ \frac{\sum_{i=1}^{r} \sum_{j=1}^{h}\left(t_{i j}^{+\mu u}-t_{i j}^{-\mu u}\right)}{2}-2\left(t_{r h}^{+\mu u}-t_{11}^{+\mu u}\right) \text { if } t_{i j}^{+\mu u}<t_{i j}^{-\mu u}\end{array} ;\right.$

$\left\|T_{\xi}^{\mu l}\right\|=\left\{\begin{array}{cc}\frac{\sum_{i=1}^{r} \sum_{j=1}^{h}\left(t_{i j}^{+\mu l}-t_{i j}^{-\mu l}\right)}{2} & \text { if } t_{i j}^{+\mu l} \geq t_{i j}^{-\mu l} \\ \frac{\sum_{i=1}^{r} \sum_{j=1}^{h}\left(t_{i j}^{+\mu l}-t_{i j}^{-\mu l}\right)}{2}-2\left(t_{r h}^{+\mu l}-t_{11}^{+\mu l}\right) & \text { if } t_{i j}^{+\mu l}<t_{i j}^{-\mu l}\end{array} ;\right.$

$\left\|T_{\xi}^{v u}\right\|=\left\{\begin{array}{cc}\frac{\sum_{i=1}^{r} \sum_{j=1}^{h}\left(t_{i j}^{+v u}-t_{i j}^{-v u}\right)}{2} \quad \text { if } t_{i j}^{+v u} \geq t_{i j}^{-v u} \\ \frac{\sum_{i=1}^{r} \sum_{j=1}^{h}\left(t_{i j}^{+v u}-t_{i j}^{-v u}\right)}{2}-2\left(t_{r h}^{+v u}-t_{11}^{+v u}\right) \text { if } t_{i j}^{+v u}<t_{i j}^{-v u}\end{array} ;\right.$

$\left\|T_{\xi}^{v l}\right\|=\left\{\begin{array}{cc}\frac{\sum_{i=1}^{r} \sum_{j=1}^{h}\left(t_{i j}^{+v l}-t_{i j}^{-v l}\right)}{2} \quad \text { if } t_{i j}^{+v l} \geq t_{i j}^{-v l} \\ \frac{\sum_{i=1}^{r} \sum_{j=1}^{h}\left(t_{i j}^{+v l}-t_{i j}^{-v l}\right)}{2}-2\left(t_{r h}^{+v l}-t_{11}^{+v l}\right) \text { if } t_{i j}^{+v l}<t_{i j}^{-v l}\end{array} ;\right.$

$t_{i j}^{+\mu u}=\max _{i} \mu_{i j}^{u}, t_{i j}^{+\mu l}=\max _{i} \mu_{i j}^{l}, t_{i j}^{-\mu u}=\min _{i} \mu_{i j}^{u}, t_{i j}^{-\mu u}=\min _{i} \mu_{i j}^{l} ;$

$t_{i j}^{+v u}=\max _{i} v_{i j}^{u}, t_{i j}^{+v l}=\max _{i} v_{i j}^{l}, t_{i j}^{-v u}=\min _{i} v_{i j}^{u}, t_{i j}^{-v u}=\min _{i} v_{i j}^{l}$.

3.3. Calculating the distance between $\partial_{e}$ and $\bar{\partial}$ based on Definition 3 with Eq. (27).

$$
\operatorname{Dis}\left(\partial_{e}, \bar{\partial}\right)=\sqrt{\frac{1}{2}\left(\left(\mu_{\partial_{e}}-\mu_{\bar{\partial}}\right)^{2}+\left(v_{\partial_{e}}-v_{\bar{\partial}}\right)^{2}\right)} ;
$$

$$
\bar{\partial}=\left[\prod_{e=1}^{E}\left(\mu^{e}\right)^{(1 / e)}, 1-\prod_{e=1}^{E}\left(1-v^{e}\right)^{(1 / e)}\right] .
$$

3.4. Computing the DMs' weights with Eq. (29) based on closeness to the average ideal solution.

Furthermore, Eq. (30) obtains the weight of each DM.

$$
\begin{aligned}
& W^{e}=\frac{\sum_{e=1}^{E} \operatorname{Dis}\left(\partial_{e}, \bar{\partial}\right)}{\operatorname{Dis}\left(\partial_{e}, \bar{\partial}\right)} ; \\
& w^{e}=\frac{W^{e}}{\sum_{e=1}^{E} W^{e}} .
\end{aligned}
$$

4. Calculating the criteria weights with WASPAS method under IVIF condition.

4.1. Constructing the matrix based on the DMs' opinions and DMs' weights.

$$
\tilde{\psi}_{i j}=\begin{gathered}
D_{1} \\
R_{1} \\
\vdots \\
R_{r}\left[\begin{array}{ccc}
\tilde{\psi}_{11} & \cdots & \tilde{\psi}_{1 e} \\
\vdots & \ddots & \vdots \\
\tilde{\psi}_{r 1} & \cdots & \tilde{\psi}_{r e}
\end{array}\right] .
\end{gathered}
$$

4.2. Computing the weighted sum model (WSM) and weighted product model (WPM) with Eqs (32) and (33), respectively.

$$
\begin{aligned}
& \tilde{\zeta}_{i}=\sum_{e=1}^{E} w^{e} \tilde{\psi}_{i e} ; \\
& \tilde{\varphi}_{i}=\prod_{e=1}^{E} w^{e} \tilde{\psi}_{i e} .
\end{aligned}
$$

4.3. Obtaining the aggregated measure of the WASPAS approach for each criterion with Eq. (34).

$$
\tilde{\varrho}_{i}=1 \times \tilde{\varphi}_{i}+(1-1) \times \tilde{\zeta}_{i},
$$

where $\mathrm{l}$ is the aggregating coefficient of decision accuracy. It is extended to approximate the precision of WASPAS based on primary criteria identity and when $\imath \in[0,1]$. In addition, when $r=0$, and $\imath=1$, WASPAS is changed to the WPM and the WSM, respectively. In this paper, 1 equals 0.5 .

5. Aggregating the normalized decision matrix with weights of the DMs based on Definition 5.

$$
\begin{aligned}
& \tilde{\tau}_{i j}=\underset{e=1}{E} w^{e} \eta_{i j}^{e}= \\
& \left(\left[1-\prod_{e=1}^{E}\left(1-\mu_{i j}^{\eta e l}\right)^{w^{e}}, 1-\prod_{e=1}^{E}\left(1-\mu_{i j}^{\eta e u}\right)^{w^{e}}\right],\left[\prod_{e=1}^{E} v_{i j}^{\eta e l^{w^{e}}}, \prod_{e=1}^{E} v_{i j}^{\eta e u^{w^{e}}}\right]\right) .
\end{aligned}
$$

6. Computing the weighted normalized decision matrix with Eq. (36).

$$
\tilde{\pi}_{i j}=\tilde{\varrho}_{i} \otimes \tilde{\tau}_{i j}=\left[\begin{array}{ccc}
\tilde{\varrho}_{1} \otimes \tilde{\tau}_{11} & \cdots & \tilde{\varrho}_{1} \otimes \tilde{\tau}_{1 h} \\
\vdots & \ddots & \vdots \\
\tilde{\varrho}_{r} \otimes \tilde{\tau}_{r 1} & \cdots & \tilde{\varrho}_{r} \otimes \tilde{\tau}_{r h}
\end{array}\right] .
$$

7. Calculating the border approximation area vector $\tilde{\chi}_{i}$ with Eq. (37). 


$$
\begin{gathered}
\tilde{\chi}_{i}=\left[\tilde{\chi}_{1}, \ldots, \tilde{\chi}_{r}\right] ; \\
\tilde{\chi}_{i}=\left[\prod_{j=1}^{h}\left(\mu_{i j}^{l}\right)^{(1 / h)}, \prod_{j=1}^{h}\left(\mu_{i j}^{u}\right)^{(1 / h)}\right],\left[1-\prod_{j=1}^{h}\left(1-v_{i j}^{l}\right)^{(1 / h)}, 1-\prod_{j=1}^{h}\left(1-v_{i j}^{u}\right)^{(1 / h)}\right] .
\end{gathered}
$$

8. Calculating the IVIF-RPR of each alternative with Eqs (39)-(46)

$$
\begin{aligned}
& A_{i j}=\left[\begin{array}{ccc}
\Delta_{P^{*}}\left(\tilde{\pi}_{11}, \overline{\tilde{\chi}}_{1}\right) & \cdots & \Delta_{P^{*}}\left(\tilde{\pi}_{1 h}, \overline{\tilde{\chi}}_{h}\right) \\
\vdots & \ddots & \vdots \\
\Delta_{P^{*}}\left(\tilde{\pi}_{r 1}, \overline{\tilde{\chi}}_{1}\right) & \cdots & \Delta_{P^{*}}\left(\tilde{\pi}_{r h}, \overline{\tilde{\chi}}_{h}\right)
\end{array}\right] ; \\
& Q_{i j}=\Delta_{P^{*}}\left(\tilde{\pi}_{i j}, \overline{\tilde{\chi}}_{i}\right)=\frac{1}{2}\left[\Delta_{P^{*}}\left(\tilde{\pi}_{i j}^{l}, \overline{\tilde{\chi}}_{i}^{l}\right)+\Delta_{P^{*}}\left(\tilde{\pi}_{i j}^{u}, \overline{\tilde{\chi}}_{i}^{u}\right)\right]=
\end{aligned}
$$

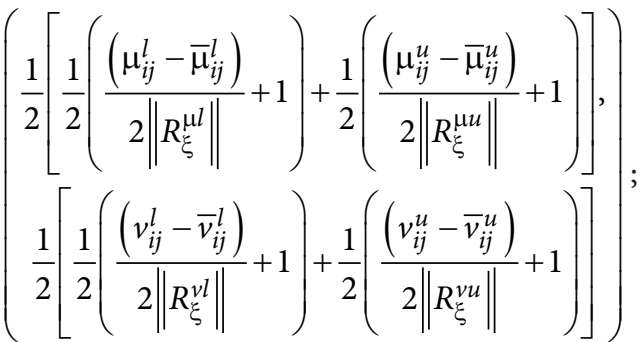

$$
\begin{aligned}
& \left\|R_{\xi}^{\mu u}\right\|=\left\{\begin{array}{cc}
\frac{\sum_{i=1}^{r} \sum_{j=1}^{h}\left(r_{i j}^{+\mu u}-r_{i j}^{-\mu u}\right)}{2} & \text { if } r_{i j}^{+\mu u} \geq r_{i j}^{-\mu u} \\
\frac{\sum_{i=1}^{r} \sum_{j=1}^{h}\left(r_{i j}^{+\mu u}-r_{i j}^{-\mu u}\right)}{2}-2\left(r_{r h}^{+\mu u}-r_{11}^{+\mu u}\right) & \text { if } r_{i j}^{+\mu u}<r_{i j}^{-\mu u}
\end{array} ;\right. \\
& \left\|R_{\xi}^{\mu l}\right\|=\left\{\begin{array}{cc}
\frac{\sum_{i=1}^{r} \sum_{j=1}^{h}\left(r_{i j}^{+\mu l}-r_{i j}^{-\mu l}\right)}{2} & \text { if } r_{i j}^{+\mu l} \geq r_{i j}^{-\mu l} \\
\frac{\sum_{i=1}^{r} \sum_{j=1}^{h}\left(r_{i j}^{+\mu l}-r_{i j}^{-\mu l}\right)}{2}-2\left(r_{r h}^{+\mu l}-r_{11}^{+\mu l}\right) & \text { if } r_{i j}^{+\mu l}<r_{i j}^{-\mu l}
\end{array}\right. \\
& \left\|R_{\xi}^{v u}\right\|=\left\{\begin{array}{cc}
\frac{\sum_{i=1}^{r} \sum_{j=1}^{h}\left(r_{i j}^{+v u}-r_{i j}^{-v u}\right)}{2} & \text { if } r_{i j}^{+v u} \geq r_{i j}^{-v u} \\
\frac{\sum_{i=1}^{r} \sum_{j=1}^{h}\left(r_{i j}^{+v u}-r_{i j}^{-v v}\right)}{2}-2\left(r_{r h}^{+v u}-r_{11}^{+v u}\right) & \text { if } r_{i j}^{+v u}<r_{i j}^{-v u}
\end{array}\right. \\
& \left\|R_{\xi}^{v l}\right\|=\left\{\begin{array}{cc}
\frac{\sum_{i=1}^{r} \sum_{j=1}^{h}\left(r_{i j}^{+v l}-r_{i j}^{-v l}\right)}{2} & \text { if } r_{i j}^{+v l} \geq r_{i j}^{-v l} \\
\frac{\sum_{i=1}^{r} \sum_{j=1}^{h}\left(r_{i j}^{+v l}-r_{i j}^{-v l}\right)}{2}-2\left(r_{r h}^{+v l}-r_{11}^{+v l}\right) & \text { if } r_{i j}^{+v l}<r_{i j}^{-v l}
\end{array}\right.
\end{aligned}
$$$$
r_{i j}^{+\mu u}=\max _{i} \mu_{i j}^{u}, r_{i j}^{+\mu l}=\max _{i} \mu_{i j}^{l}, r_{i j}^{-\mu u}=\min _{i} \mu_{i j}^{u}, r_{i j}^{-\mu u}=\min _{i} \mu_{i j}^{l}
$$

$$
r_{i j}^{+v u}=\max _{i} v_{i j}^{u}, r_{i j}^{+v l}=\max _{i} v_{i j}^{l}, r_{i j}^{-v u}=\min _{i} v_{i j}^{u}, r_{i j}^{-v u}=\min _{i} v_{i j}^{l} .
$$

9. Obtaining the final value of each alternative with Eq. (47).

$$
\rho_{j}=\sum_{i=1}^{r} \Delta_{P^{*}}\left(\tilde{\pi}_{i j}, \overline{\tilde{\chi}}_{i}\right) .
$$

10. Calculating the distance between $\rho_{j}$ and $\bar{\rho}$ based on Definition 3 with Eq. (48).

$$
\begin{aligned}
& \operatorname{Dis}\left(\rho_{j}, \bar{\rho}\right)=\sqrt{\frac{1}{2}\left(\left(\mu_{\rho_{j}}-\mu_{\bar{\rho}}\right)^{2}+\left(v_{\rho_{j}}-v_{\bar{\rho}}\right)^{2}\right)} ; \\
& \bar{\rho}=\left[\prod_{j=1}^{h}\left(\mu^{j}\right)^{(1 / h)}, 1-\prod_{j=1}^{h}\left(1-v^{j}\right)^{(1 / h)}\right] .
\end{aligned}
$$

11. Computing the final value to rank alternatives with Eq. (50). Also, the alternatives are ranked in descending order.

$$
C^{j}=\frac{\sum_{j=1}^{h} \operatorname{Dis}\left(\rho_{j}, \bar{\rho}\right)}{\operatorname{Dis}\left(\rho_{j}, \bar{\rho}\right)} .
$$

Furthermore, the structure of the introduced method is presented in Figure 1.

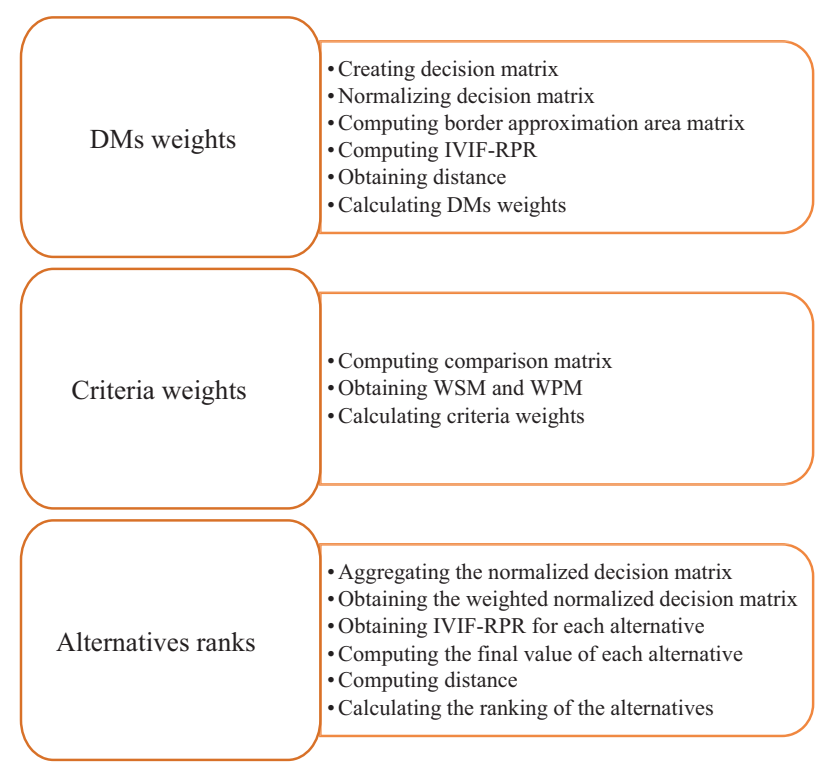

Figure 1. Structure of the proposed IVIF decision-making model

\section{Case study}

This section examines a real-case study of the railway construction projects in Serbia based on the literature (Belošević et al., 2018) to show the performance of the introduced model in the selection and evaluation of the IP problem. This case is related to the railway of Pančevo-Vršac; this rail line is depicted in Figure 2. The railway line can be utilized to help people to transfer among two far nodes, and this line aids the persons to travel to the cities that are located among source and destination nodes easily. In this regard, this study applies 7 types of criteria, 3 DMs, and 4 different alternatives. 


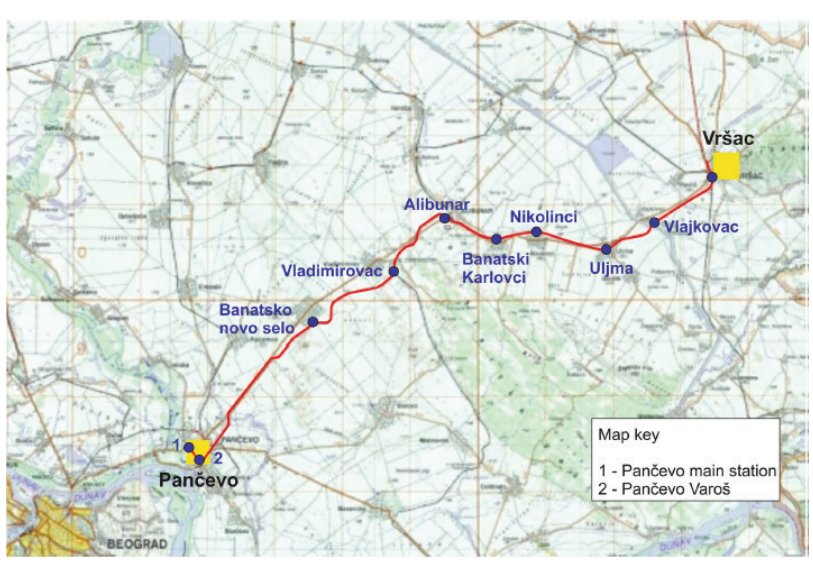

Figure 2. Railway line of Pančevo-Vršac

Hence, $D_{1}$ has an experience in railroad frameworks and alignment design, $D_{2}$ has an expertise in railway practice and transportation economics, and $D_{3}$ has a skill in spatial planning and environmental conservation. Also, the main criteria are included financial provisions $\left(R_{1}\right)$, quality of the rail service $\left(R_{2}\right)$, safety performance $\left(R_{3}\right)$, risks of the project $\left(R_{4}\right)$, transportation politics $\left(R_{5}\right)$, economic impacts $\left(R_{6}\right)$, and environmental effect $\left(R_{7}\right)$. The first and fourth criteria have a cost nature and their others have a benefits nature. The first alternative $\left(M_{2}\right)$ introduces setting all residual railroads equipped with signs and some type of safety tool. The second $\left(M_{3}\right)$ alternative proposes setting all residual railroads equipped with obstacles and alarms as active traffic control systems. The third alternative $\left(M_{4}\right)$ considers setting all railroads at a separated rating. The $\left(M_{1}\right)$ is relevant to the lowest rank alternative

Table 1. Linguistic phrases for assessing the alternatives

\begin{tabular}{|l|c|}
\hline \multicolumn{1}{|c|}{ Linguistic term } & Value \\
\hline Very strong (VS) & $([0.73,0.83],[0.00,0.13])$ \\
\hline Strong $(\mathrm{S})$ & $([0.63,0.73],[0.10,0.23])$ \\
\hline Medium $(\mathrm{M})$ & $([0.43,0.53],[0.30,0.43])$ \\
\hline Weak $(\mathrm{W})$ & $([0.15,0.29],[0.45,0.64])$ \\
\hline Very weak (VW) & $([0.00,0.14],[0.60,0.79])$ \\
\hline
\end{tabular}

Table 2. Linguistic values for assessing the criteria

\begin{tabular}{|l|c|}
\hline \multicolumn{1}{|c|}{ Linguistic term } & Value \\
\hline Very high $(\mathrm{VH})$ & $([0.90,0.90],[0.10,0.10])$ \\
\hline High $(\mathrm{H})$ & $([0.40,0.76],[0.00,0.21])$ \\
\hline Medium $(\mathrm{M})$ & $([0.15,0.51],[0.25,0.46])$ \\
\hline Low $(\mathrm{L})$ & $([0.00,0.36],[0.40,0.61])$ \\
\hline Very low $(\mathrm{VL})$ & $([0.10,0.10],[0.90,0.90])$ \\
\hline
\end{tabular}

that is called the do-nothing alternative. Afterward, linguistic variables are applied to evaluate the alternatives in Table 1. This table provides the linguistic variables in five scales for judging the main alternatives of the problem based on three DMs' opinions. Moreover, the linguistic terms are considered in another scale to assess the problem criteria with an opinion of each DM in Table 2. For this reason, Table 2 provides these five measures to compute the assessment value of each criterion (Hajek \& Froelich, 2019).

The decision matrix based on linguistic judgment is presented in Table 3. This table provides the decision matrix and rating of each alternative with respect to each criterion by DMs with the linguistic terms. Furthermore, the linguistic comparison between criteria and experts' judgment is given in Table 4. These are completed with the experts' opinions that are received from their experiences and knowledge. The judgments of Table 3 are provided from VW to VS, and the judgments based on DMs opinions in Table 4 are presented from VL to VH by five scales.

Table 3. Rating of alternatives with regard to criteria evaluated by DMs

\begin{tabular}{|c|c|c|c|c|c|c|c|c|}
\hline Alternatives & DMs & $R_{1}$ & $R_{2}$ & $R_{3}$ & $R_{4}$ & $R_{5}$ & $R_{6}$ & $R_{7}$ \\
\hline$M_{1}$ & \multirow[t]{4}{*}{$D_{1}$} & $\mathrm{~W}$ & VW & VW & $\mathrm{S}$ & $\mathrm{W}$ & $\mathrm{W}$ & $\mathrm{W}$ \\
\hline$M_{2}$ & & VS & $\mathrm{W}$ & $S$ & VS & VW & $\mathrm{S}$ & $\mathrm{W}$ \\
\hline$M_{3}$ & & $\mathrm{M}$ & S & M & $S$ & $\mathrm{~S}$ & $\mathrm{M}$ & $\mathrm{W}$ \\
\hline$M_{4}$ & & VW & VS & VS & VW & $\mathrm{M}$ & VS & VW \\
\hline$M_{1}$ & \multirow[t]{4}{*}{$D_{2}$} & $\mathrm{~W}$ & VW & $\mathrm{W}$ & $S$ & $\mathrm{~W}$ & VW & $\mathrm{W}$ \\
\hline$M_{2}$ & & VS & $\mathrm{W}$ & $\mathrm{W}$ & $S$ & $\mathrm{~W}$ & $\mathrm{~W}$ & $S$ \\
\hline$M_{3}$ & & $S$ & $S$ & $S$ & $\mathrm{M}$ & VS & $S$ & $\mathrm{M}$ \\
\hline$M_{4}$ & & $\mathrm{M}$ & VS & VS & $\mathrm{W}$ & $\mathrm{S}$ & VS & $\mathrm{W}$ \\
\hline$M_{1}$ & \multirow[t]{4}{*}{$D_{3}$} & $\mathrm{M}$ & $\mathrm{W}$ & $\mathrm{M}$ & $\mathrm{S}$ & $\mathrm{W}$ & $\mathrm{W}$ & $\mathrm{VW}$ \\
\hline$M_{2}$ & & $\mathrm{~S}$ & $M$ & $\mathrm{~S}$ & $S$ & $\mathrm{~W}$ & $\mathrm{M}$ & $S$ \\
\hline$M_{3}$ & & $S$ & S & $\mathrm{F}$ & $S$ & $S$ & $\mathrm{~S}$ & $\mathrm{~W}$ \\
\hline$M_{4}$ & & $\mathrm{~W}$ & $S$ & $\mathrm{~W}$ & $\mathrm{~W}$ & S & S & VW \\
\hline
\end{tabular}

Table 4. Importance of criteria evaluated by DMs

\begin{tabular}{|c|c|c|c|}
\hline Criteria & $D_{1}$ & $D_{2}$ & $D_{3}$ \\
\hline$R_{1}$ & $\mathrm{VH}$ & $\mathrm{H}$ & $\mathrm{M}$ \\
\hline$R_{2}$ & $\mathrm{H}$ & $\mathrm{VH}$ & $\mathrm{M}$ \\
\hline$R_{3}$ & $\mathrm{H}$ & $\mathrm{VH}$ & $\mathrm{H}$ \\
\hline$R_{4}$ & $\mathrm{VH}$ & $\mathrm{M}$ & $\mathrm{VL}$ \\
\hline$R_{5}$ & $\mathrm{H}$ & $\mathrm{VH}$ & $\mathrm{M}$ \\
\hline$R_{6}$ & $\mathrm{M}$ & $\mathrm{VH}$ & $\mathrm{L}$ \\
\hline$R_{7}$ & $\mathrm{M}$ & $\mathrm{L}$ & $\mathrm{VH}$ \\
\hline
\end{tabular}


Table 5. Normalized decision matrix

\begin{tabular}{|c|c|c|c|c|c|c|c|c|}
\hline Alternatives & DMs & $R_{1}$ & $R_{2}$ & $R_{3}$ & $R_{4}$ & $R_{5}$ & $R_{6}$ & $R_{7}$ \\
\hline$M_{1}$ & \multirow[t]{4}{*}{$D_{1}$} & $\begin{array}{l}{[0.17,0.28],} \\
[0.56,0.58])\end{array}$ & $\begin{array}{l}([0.00,0.12], \\
[0.79,0.75])\end{array}$ & $\begin{array}{l}([0.00,0.11], \\
[0.88,0.84])\end{array}$ & $\begin{array}{l}{[0.55,0.55],} \\
[0.16,0.27])\end{array}$ & $\begin{array}{l}([0.19,0.30], \\
[0.55,0.57])\end{array}$ & $\begin{array}{l}([0.14,0.23], \\
[0.82,0.79])\end{array}$ & $\begin{array}{l}([0.58,0.56], \\
[0.46,0.47])\end{array}$ \\
\hline$M_{2}$ & & $\begin{array}{l}([0.85,0.80], \\
[0.00,0.12])\end{array}$ & $\begin{array}{l}([0.15,0.25], \\
[0.59,0.61])\end{array}$ & $\begin{array}{l}([0.60,0.59] \\
[0.15,0.25])\end{array}$ & $\begin{array}{l}([0.63,0.62], \\
[0.00,0.15])\end{array}$ & $\begin{array}{l}([0.00,0.15], \\
[0.74,0.70])\end{array}$ & $\begin{array}{l}([0.59,0.58], \\
[0.18,0.28])\end{array}$ & $\begin{array}{c}([0.58,0.56] \\
[0.46,0.47])\end{array}$ \\
\hline$M_{3}$ & & $\begin{array}{l}([0.50,0.51] \\
[0.37,0.39])\end{array}$ & $\begin{array}{l}([0.65,0.63], \\
[0.13,0.22])\end{array}$ & $\begin{array}{l}([0.41,0.43] \\
[0.44,0.46])\end{array}$ & $\begin{array}{l}([0.55,0.55], \\
[0.16,0.27])\end{array}$ & $\begin{array}{l}([0.81,0.76], \\
[0.12,0.20])\end{array}$ & $\begin{array}{l}([0.40,0.42], \\
[0.55,0.53])\end{array}$ & $\begin{array}{c}([0.58,0.56] \\
[0.46,0.47])\end{array}$ \\
\hline$M_{4}$ & & $\begin{array}{c}([0.00,0.14], \\
[0.74,0.71])\end{array}$ & $\begin{array}{l}([0.75,0.72] \\
[0.00,0.12])\end{array}$ & $\begin{array}{l}([0.69,0.67], \\
[0.00,0.14])\end{array}$ & $\begin{array}{l}([0.00,0.11], \\
[0.97,0.91])\end{array}$ & $\begin{array}{l}([0.55,0.55], \\
[0.37,0.38])\end{array}$ & $\begin{array}{l}([0.68,0.66] \\
[0.00,0.16])\end{array}$ & $\begin{array}{l}([0.00,0.27] \\
[0.61,0.58])\end{array}$ \\
\hline$M_{1}$ & \multirow[t]{4}{*}{$D_{2}$} & $\begin{array}{l}([0.14,0.23], \\
[0.82,0.79])\end{array}$ & $\begin{array}{l}([0.00,0.12], \\
[0.79,0.75])\end{array}$ & $\begin{array}{l}([0.15,0.25], \\
[0.70,0.68])\end{array}$ & $\begin{array}{l}([0.63,0.61], \\
[0.18,0.27])\end{array}$ & $\begin{array}{l}([0.15,0.25], \\
[0.70,0.68])\end{array}$ & $\begin{array}{l}([0.00,0.12], \\
[0.79,0.75])\end{array}$ & $\begin{array}{l}([0.19,0.29], \\
[0.63,0.62])\end{array}$ \\
\hline$M_{2}$ & & $\begin{array}{c}([0.68,0.66], \\
[0.00,0.16])\end{array}$ & $\begin{array}{l}([0.15,0.25], \\
[0.59,0.61])\end{array}$ & $\begin{array}{c}([0.15,0.25], \\
[0.70,0.68])\end{array}$ & $\begin{array}{l}([0.63,0.61], \\
[0.18,0.27])\end{array}$ & $\begin{array}{c}([0.15,0.25], \\
[0.70,0.68])\end{array}$ & $\begin{array}{l}([0.15,0.25], \\
[0.59,0.61])\end{array}$ & $\begin{array}{l}([0.80,0.74], \\
[0.14,0.22])\end{array}$ \\
\hline$M_{3}$ & & $\begin{array}{l}([0.59,0.58], \\
[0.18,0.28])\end{array}$ & $\begin{array}{l}([0.65,0.63], \\
[0.13,0.22])\end{array}$ & $\begin{array}{l}([0.64,0.62], \\
[0.16,0.24])\end{array}$ & $\begin{array}{l}([0.43,0.44], \\
[0.54,0.51])\end{array}$ & $\begin{array}{l}([0.74,0.70], \\
[0.00,0.14])\end{array}$ & $\begin{array}{l}([0.65,0.63], \\
[0.13,0.22])\end{array}$ & $\begin{array}{l}([0.54,0.53] \\
[0.42,0.42])\end{array}$ \\
\hline$M_{4}$ & & $\begin{array}{l}([0.40,0.42] \\
[0.55,0.53])\end{array}$ & $\begin{array}{l}([0.75,0.72] \\
[0.00,0.12])\end{array}$ & $\begin{array}{l}([0.74,0.70], \\
[0.00,0.14])\end{array}$ & $\begin{array}{l}([0.15,0.24], \\
[0.80,0.76])\end{array}$ & $\begin{array}{l}([0.64,0.62], \\
[0.16,0.24])\end{array}$ & $\begin{array}{l}([0.75,0.72], \\
[0.00,0.12])\end{array}$ & $\begin{array}{l}([0.19,0.29] \\
[0.63,0.62])\end{array}$ \\
\hline$M_{1}$ & \multirow[t]{4}{*}{$D_{3}$} & $\begin{array}{l}([0.43,0.44], \\
[0.54,0.51])\end{array}$ & $\begin{array}{l}([0.15,0.24], \\
[0.80,0.76])\end{array}$ & $\begin{array}{l}([0.48,0.49], \\
[0.48,0.47])\end{array}$ & $\begin{array}{l}([0.57,0.56], \\
[0.21,0.31])\end{array}$ & $\begin{array}{l}([0.16,0.26], \\
[0.69,0.67])\end{array}$ & $\begin{array}{l}([0.15,0.24], \\
[0.80,0.76])\end{array}$ & $\begin{array}{l}([0.00,0.17], \\
[0.62,0.60])\end{array}$ \\
\hline$M_{2}$ & & $\begin{array}{l}([0.63,0.61] \\
[0.18,0.27])\end{array}$ & $\begin{array}{l}([0.43,0.44], \\
[0.54,0.51])\end{array}$ & $\begin{array}{l}([0.71,0.67], \\
[0.16,0.25])\end{array}$ & $\begin{array}{l}([0.57,0.56], \\
[0.21,0.31])\end{array}$ & $\begin{array}{l}([0.16,0.26], \\
[0.69,0.67])\end{array}$ & $\begin{array}{l}([0.43,0.44], \\
[0.54,0.51])\end{array}$ & $\begin{array}{c}([0.97,0.90] \\
[0.10,0.18])\end{array}$ \\
\hline$M_{3}$ & & $\begin{array}{l}([0.63,0.61] \\
[0.18,0.27])\end{array}$ & $\begin{array}{l}([0.63,0.61], \\
[0.18,0.27])\end{array}$ & $\begin{array}{l}([0.48,0.49], \\
[0.48,0.47])\end{array}$ & $\begin{array}{l}([0.57,0.56] \\
[0.21,0.31])\end{array}$ & $\begin{array}{l}([0.69,0.66] \\
[0.15,0.24])\end{array}$ & $\begin{array}{l}([0.63,0.61] \\
[0.18,0.27])\end{array}$ & $\begin{array}{l}([0.23,0.36] \\
[0.47,0.49])\end{array}$ \\
\hline$M_{4}$ & & $\begin{array}{l}([0.15,0.24] \\
[0.80,0.76])\end{array}$ & $\begin{array}{l}([0.63,0.61], \\
[0.18,0.27])\end{array}$ & $\begin{array}{l}([0.17,0.27], \\
[0.72,0.70])\end{array}$ & $\begin{array}{l}([0.14,0.22], \\
[0.93,0.85])\end{array}$ & $\begin{array}{c}([0.69,0.66] \\
[0.15,0.24])\end{array}$ & $\begin{array}{l}([0.63,0.61] \\
[0.18,0.27])\end{array}$ & $\begin{array}{l}([0.00,0.17] \\
[0.62,0.60])\end{array}$ \\
\hline
\end{tabular}

In this regard, Table 5 presents the normalized decision matrix that is computed with Eq. (17). In this formulation, the normalized decision matrix is computed based on the membership and non-membership degrees with lower bound and upper bound values separately. After that, a distance and a weight of DMs are computed with Eqs (27), (29), and (30) that are generated in Table 6. In this regard, the distance value, Dis $\left(\partial_{e}, \bar{\partial}\right)$, is presented based on Euclidean distance formulation, and is computed from the opinion of the DMs. Further $W^{e}$ more, $w^{e}$ are the values of the normalized weights that are computed from each $W^{e}$ value divided on the summation of $W^{e}$ values. As can be seen, the second DM has a high priority than others, and the opinion is superior to others. This person has expertise in railway practice and transportation economics.

Also, the amounts of $\tilde{\zeta}_{i}$, and $\tilde{\varrho}_{i}$ are presented in Table 7. The WSM is computed from the weighted decision matrix with aggregating opinions of the DMs. Therefore, the aggregation of WASPAS value $\tilde{\varrho}_{i}$ is obtained from in-

Table 6. Weights of the DMs

\begin{tabular}{|c|c|c|c|}
\hline DMs & Dis $\left(\partial_{e}, \bar{\partial}\right)$ & $W^{e}$ & $w^{e}$ \\
\hline$D_{1}$ & 0.55 & 3.47 & 0.37 \\
\hline$D_{2}$ & 0.52 & 3.67 & 0.39 \\
\hline$D_{3}$ & 0.84 & 2.28 & 0.24 \\
\hline
\end{tabular}

tegrating the WSM and WPM with a specific procedure. These are computed from Eqs (32) and (34). The IVIF criteria weights show that the third criterion with higher membership degree and lower non-membership value has a great value than other criteria. This criterion is related to safety performance.

In addition, the IVIF-RPR of each alternative $\left(Q_{i j}\right)$ is depicted in Table 8 that is computed with Eq. (40). Afterward, final alternatives values $\left(\rho_{j}\right)$, Dis $\left(\rho_{j}, \bar{\rho}\right)$, and $C^{j}$ are introduced in Table 9 that are obtained from Eqs (47), (48), and $(50)$, respectively. The distance measure $\left(\operatorname{Dis}\left(\rho_{j}, \bar{\rho}\right)\right)$ aggregates the fuzzy values and changes them to the crisp quantity. In this respect, the distance computation formulation is presented from Euclidean procedure. Finally, the collective measure index $\left(C^{j}\right)$ shows the ranking score of the alternatives.

Table 7. Criteria weights

\begin{tabular}{|c|c|c|}
\hline Criteria & $\tilde{\zeta}_{i}$ & $\tilde{\varrho}_{i}$ \\
\hline$R_{1}$ & $([0.52,0.75],[0.10,0.23])$ & $([0.26,0.38],[0.05,0.12])$ \\
\hline$R_{2}$ & $([0.53,0.75],[0.10,0.23])$ & $([0.27,0.38],[0.05,0.11])$ \\
\hline$R_{3}$ & $([0.59,0.81],[0.04,0.17])$ & $([0.30,0.42],[0.02,0.08])$ \\
\hline$R_{4}$ & $([0.41,0.55],[0.35,0.43])$ & $([0.21,0.28],[0.18,0.22])$ \\
\hline$R_{5}$ & $([0.53,0.75],[0.10,0.23])$ & $([0.27,0.38],[0.05,0.11])$ \\
\hline$R_{6}$ & $([0.41,0.63],[0.23,0.36])$ & $([0.20,0.32],[0.11,0.18])$ \\
\hline$R_{7}$ & $([0.27,0.55],[0.27,0.43])$ & $([0.14,0.28],[0.14,0.22])$ \\
\hline
\end{tabular}


Table 8. Amount of $Q_{i j}$

\begin{tabular}{|c|c|c|c|c|c|c|c|}
\hline Alternatives & $R_{1}$ & $R_{2}$ & $R_{3}$ & $R_{4}$ & $R_{5}$ & $R_{6}$ & $R_{7}$ \\
\hline$M_{1}$ & {$[1.08,1.07]$} & {$[1.03,1.09]$} & {$[1.08,1.05]$} & {$[1.11,1.06]$} & {$[1.06,1.07]$} & {$[1.03,1.16]$} & {$[1.06,1.03]$} \\
\hline$M_{2}$ & {$[1.19,1.01]$} & {$[1.08,1.06]$} & {$[1.15,1.02]$} & {$[1.12,1.03]$} & {$[1.04,1.08]$} & {$[1.09,1.08]$} & {$[1.13,1.06]$} \\
\hline$M_{3}$ & {$[1.15,1.03]$} & {$[1.17,1.02]$} & {$[1.15,1.02]$} & {$[1.10,1.08]$} & {$[1.19,1.01]$} & {$[1.12,1.06]$} & {$[1.08,1.11]$} \\
\hline$M_{4}$ & {$[1.06,1.07]$} & {$[1.19,1.01]$} & {$[1.17,1.01]$} & {$[1.03,1.24]$} & {$[1.16,1.03]$} & {$[1.14,1.02]$} & {$[1.03,1.15]$} \\
\hline
\end{tabular}

Table 9. Ranking of the alternatives

\begin{tabular}{|c|c|c|c|c|}
\hline Alternatives & $\rho_{j}$ & $\operatorname{Dis}\left(\rho_{j}, \bar{\rho}\right)$ & $C^{j}$ & $\begin{array}{c}\text { Final } \\
\text { ranking } \\
\text { values }\end{array}$ \\
\hline$M_{1}$ & {$[7.45,7.62]$} & 9.254 & 3.950 & 4 \\
\hline$M_{2}$ & {$[7.80,7.35]$} & 9.057 & 4.035 & 2 \\
\hline$M_{3}$ & {$[7.96,7.34]$} & 9.054 & 4.037 & 1 \\
\hline$M_{4}$ & {$[7.79,7.53]$} & 9.184 & 3.980 & 3 \\
\hline
\end{tabular}

Table 9 determines that the third alternative has high priority than other options. This alternative is related to using the alarms and active traffic control systems in all residual railroads. The notable point is about the distance value of the alternatives that the higher distance has a lower score and has a lower rank in comparing other alternatives. The lower distance and higher score values are created from the higher membership and lower nonmembership degrees in the final alternative values. Eventually, this table demonstrates that the higher membership degree has a lower non-membership value. Also, the higher degree of the membership value creates a lower distance, and the lower distance makes the high-rank value.

\section{Discussion of results}

This section examines the comparisons of IVIF-TOPSIS, IVIF-extended VIKOR (E-VIKOR) from the adapted casestudy paper, and the proposed approach for validating the introduced model. The utilized IVIF-TOPSIS method is related to the original TOPSIS under IVIF conditions. The final values of the alternatives rank are determined in Table 10 and Figure 3. This figure is determined that the introduced model has a good performance and is validated to compute the complex problem. This figure depicts that the first alternative places in the fourth-ranking position in all decision methods. Afterward, the second alternative places in the third position by IVIF-E-VIKOR method, and locates the second position by two other computing methods. Moreover, the fourth alternative places in the second position by IVIF-E-VIKOR method, and places the third position by other approaches. Finally, the third alternative places in the first position by obtaining all three different methods.
Table 10. Comparing the score values among three IVIF decision-making methods

\begin{tabular}{|c|c|c|c|}
\hline Alternatives & $\begin{array}{c}\text { Score of IVIF- } \\
\text { E-VIKOR } \\
\text { method }\end{array}$ & $\begin{array}{c}\text { Score of } \\
\text { IVIF-TOPSIS } \\
\text { method }\end{array}$ & $\begin{array}{c}\text { Score of the } \\
\text { proposed } \\
\text { approach }\end{array}$ \\
\hline$M_{1}$ & 0.352 & 0.342 & 3.950 \\
\hline$M_{2}$ & 0.359 & 0.425 & 4.035 \\
\hline$M_{3}$ & 0.484 & 0.496 & 4.037 \\
\hline$M_{4}$ & 0.473 & 0.362 & 3.980 \\
\hline
\end{tabular}

In addition, the degree of the $\Delta_{p}$ has an important role in computing the weights of the DMs. For this reason, this value change from 0.1 to 0.9 , and its impact on the final weights are depicted in Figure 4. This figure demonstrates that the final weights of the DMs change with the various values, but the second DM has high priority than others with a different degree. This point determines that the proposed approach is reliable. Also, this rate can be changed for the ranking proposed approach that is used in Eq. (40). The value of $\Delta_{p}$ changes among 0.1 to 0.9 , and their influences are demonstrated in Figure 5. This figure present that the third alternative has a high priority than other with various amount of $\Delta_{p}$. In this regard, the value of adjustment measure changes among interval values, and the final results denote that the third alternative has high priority and degree than other alternatives. The ranking method is compared in two ways, and all of them show that the proposed model is reliable and robust.

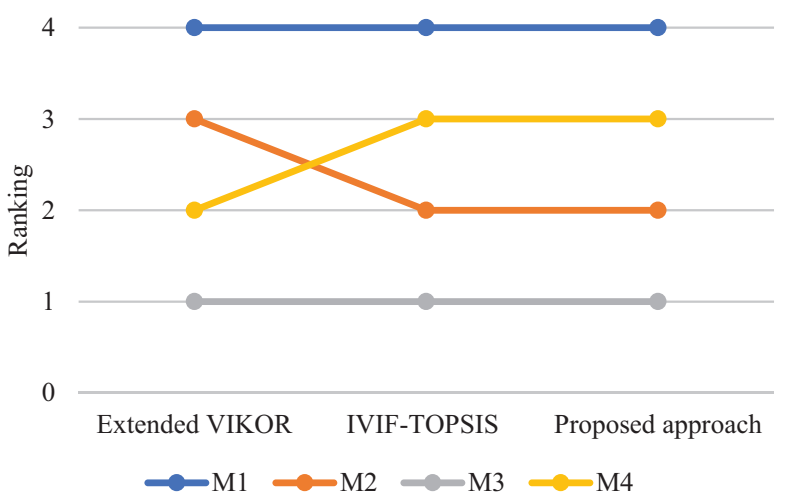

Figure 3. Comparisons of the rankings among three IVIF decision methods 


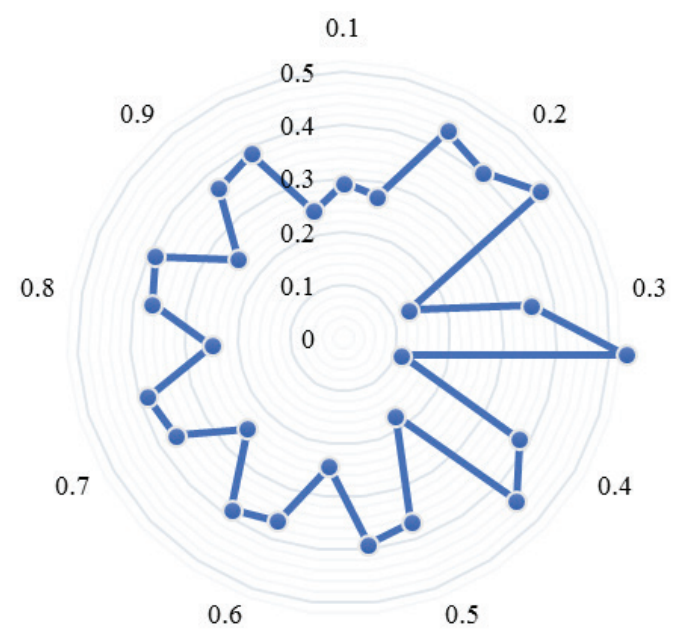

Figure 4. Effect of changing $\Delta_{p}$ value in the weighting method

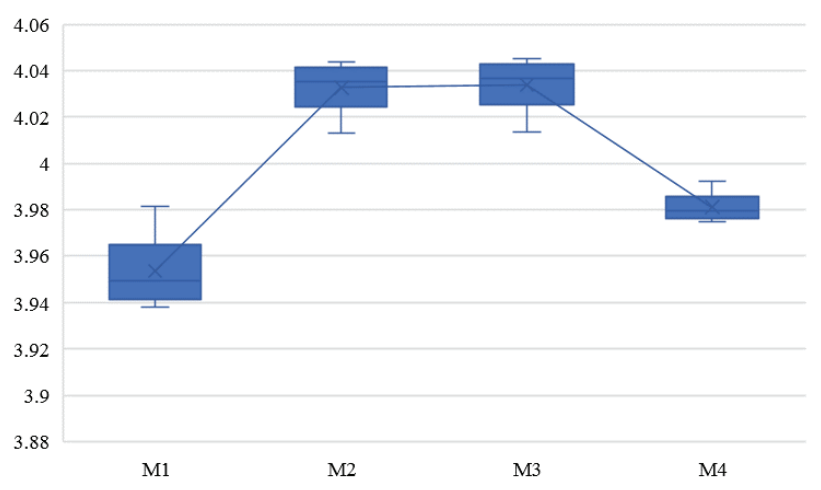

Figure 5. Effect of changing $\Delta_{p}$ value in the ranking approach

\section{Conclusion and further suggestions}

Infrastructure projects (IPs) are one of the most important issues that have fundamental effects on the quality of the lives of people in the community. In this way, the transportation system and the construction have a high position to transfer people. Introducing construction projects into infrastructure fields has been highly motivated by the government as an effective manner to evaluate and select a sustainable alternative. In this regard, multi-criteria decision-making (MCDM) techniques were developed to support the selection and evaluation alternatives in the IPs. This paper presented a new hybrid weighting and ranking approach to compute the decision makers (DMs) weights, criteria weights, and alternatives ranks, respectively. These formulations consisted of new relative preference relationmulti-attributive border approximation area comparison (RPR-MABAC), weighted aggregated sum product assessment (WASPAS), and new RPR-MABAC approaches. The first method was used to obtain the DMs' weights, and the second approach was utilized to obtain the criteria weights. The RPR was one of the computation approaches used in the border approximation area matrix. For this reason, the preference degree was obtained to compute the RPR degree. Also, WASPAS method was the distance-based method that combined the weighted sum model (WSM) and the weighted product model (WPM). Afterward, new combination ranking approach was presented to rank alternatives. This method was developed based on using the RPR degree. Moreover, this decision approach was developed in interval-valued intuitionistic (IVIF) conditions for increasing real-world application situations. Hence, a real case study of Serbia railway was applied from the literature to validate the proposed model. The final results determined that the introduced approach had high performance to compute the complex project decision, and the third alternative had superior value to others. Finally, the comparative analysis was introduced to determine the performance of the proposed approach. For this reason, the proposed model was compared with two IVIF-TOPSIS method and IVIF-extended VIKOR approaches. The final results of these three methods were similar and confirmed the performance and validation of the proposed approach. Furthermore, the sensitivity analysis was introduced based on the study of the effect of $\Delta_{p}$ on the final weighting outcomes and final ranking results. The discussion of results demonstrated that the final result of the proposed model was reliable in various conditions. Also, all of the outcomes showed that the proposed approach had a high performance to take an appropriate decision by managers and DMs in the real complex IP problems.

For the managerial insights based on the case study, this paper denotes that managers and DMs can utilize this proposed approach to solve MCDM problems in various types under uncertainty. In complex decision-making concerns, when uncertainties require to be taken, this proposed model contains some advantages; they contain maintaining simple mathematical computations and constant outcomes, considering benefit and cost values for information in the model, and high accuracy of solving the decision problem by regarding conditions of uncertainty. Practical characteristics can be considered by the proposed decision model that include infrastructure problems, construction problems, investment project assessment, and other related topics. In typical usages, managers can choose suitable criteria relevant to their requirements and assess the performance values of alternatives. When the proposed model is utilized to demonstrate the criteria weights, linguistic values can better represent the selection data of DMs for criteria and find a compatible model via pairwise comparisons to get the proper weights of criteria. Also, the proposed method can enhance the decisionmaking precision when selecting the suitable alternative and is appropriate for complex types of problems under uncertainty.

For future suggestions, the presented approach can be developed by various types of extended fuzzy sets approaches, like hesitant fuzzy sets, to deal with uncertain situations. Furthermore, it can be implemented by a decision support system (DSS) in several positions for solving complex MCDM problems. 


\section{Acknowledgements}

The authors would like to acknowledge anonymous reviewers for their valuable comments and suggestions.

\section{Author contributions}

S. Salimain and S. M. Mousavi designed the research, analyzed the data and the obtained results and developed the manuscript. J. Antuchevičienè provided extensive advice throughout the study regarding the research design, methodology and findings. All the authors have read and approved the final manuscript.

\section{Disclosure statement}

The authors declare that they have any competing financial, professional, or personal interests from other parties.

\section{References}

Arshad, H., Thaheem, M. J., Bakhtawar, B., \& Shrestha, A. (2021). Evaluation of road IPs: a life cycle sustainability-based decision-making approach. Sustainability, 13(7), 3743. https://doi.org/10.3390/su13073743

Atanassov, K. (1986). Intuitionistic fuzzy sets. Fuzzy Sets and Systems, 20(1), 87-96.

https://doi.org/10.1016/S0165-0114(86)80034-3

Atanassov, K. T. (1999). Intuitionistic fuzzy sets. In Intuitionistic fuzzy sets (pp. 1-137). Physica.

https://doi.org/10.1007/978-3-7908-1870-3_1

Atanassov, K., \& Gargov, G. (1989). Interval-valued intuitionistic fuzzy sets. Fuzzy Sets and Systems, 31(3), 343-349. https://doi.org/10.1016/0165-0114(89)90205-4

Banihashemi, S. A., Khalilzadeh, M., Antucheviciene, J., \& Šaparauskas, J. (2021). Trading off time-cost-quality in construction project scheduling problems with fuzzy SWARATOPSIS approach. Buildings, 11(9), 387. https://doi.org/10.3390/buildings11090387

Bapat, H., Sarkar, D., \& Gujar, R. (2021). Application of integrated fuzzy FCM-BIM-IoT for sustainable material selection and energy management of metro rail station box project in western India. Innovative Infrastructure Solutions, 6(2), 1-18. https://doi.org/10.1007/s41062-020-00431-7

Baušys, R., Juodagalvienè, B., Žiūrienè, R., Pankrašovaité, I., Kamarauskas, J., Usovaitè, A., \& Gaižauskas, D. (2020). The residence plot selection model for family house in Vilnius by neutrosophic WASPAS method. International Journal of Strategic Property Management, 24(3), 182-196. https://doi.org/10.3846/ijspm.2020.12107

Belošević, I., Kosijer, M., Ivić, M., \& Pavlović, N. (2018). Group decision making process for early stage evaluations of IPs using extended VIKOR method under fuzzy environment. European Transport Research Review, 10(2), 1-14. https://doi.org/10.1186/s12544-018-0318-4

Bingham, E., \& Gibson Jr, G. E. (2017). IP scope definition using project definition rating index. Journal of Management in Engineering, 33(2), 04016037. https://doi.org/10.1061/(ASCE)ME.1943-5479.0000483

Bustince, H., \& Burillo, P. (1996). Vague sets are intuitionistic fuzzy sets. Fuzzy Sets and Systems, 79(3), 403-405. https://doi.org/10.1016/0165-0114(95)00154-9
Büyüközkan, G., \& Göçer, F. (2018). An extension of ARAS methodology under interval valued intuitionistic fuzzy environment for digital supply chain. Applied Soft Computing, 69, 634-654. https://doi.org/10.1016/j.asoc.2018.04.040

Chakraborty, S., \& Zavadskas, E. K. (2014). Applications of WASPAS method in manufacturing decision making. Informatica, 25(1), 1-20. https://doi.org/10.15388/Informatica.2014.01

Chitsaz, N., \& Banihabib, M. E. (2015). Comparison of different multi criteria decision-making models in prioritizing flood management alternatives. Water Resources Management, 29(8), 2503-2525.

https://doi.org/10.1007/s11269-015-0954-6

Construction Industry Institute. (2010). Implementation Resource 268-2: Project Definition Rating Index-IPs. Austin, TX.

Davoudabadi, R., Mousavi, S. M., \& Mohagheghi, V. (2020). A new last aggregation method of multi-attributes group decision making based on concepts of TODIM, WASPAS and TOPSIS under interval-valued intuitionistic fuzzy uncertainty. Knowledge and Information Systems, 62, 1371-1391. https://doi.org/10.1007/s10115-019-01390-X

Davoudabadi, R., Mousavi, S. M., \& Mohagheghi, V. (2021). A new decision model based on DEA and simulation to evaluate renewable energy projects under interval-valued intuitionistic fuzzy uncertainty. Renewable Energy, 164, 1588-1601. https://doi.org/10.1016/j.renene.2020.09.089

Davoudabadi, R., Mousavi, S. M., Mohagheghi, V., \& Vahdani, B. (2019). Resilient supplier selection through introducing a new interval-valued intuitionistic fuzzy evaluation and decision-making framework. Arabian Journal for Science and Engineering, 44(8), 7351-7360.

https://doi.org/10.1007/s13369-019-03891-x

Dorfeshan, Y., \& Mousavi, S. M. (2020). A novel interval type-2 fuzzy decision model based on two new versions of relative preference relation-based MABAC and WASPAS methods (with an application in aircraft maintenance planning). Neural Computing and Applications, 32(8), 3367-3385. https://doi.org/10.1007/s00521-019-04184-y

Egilmez, G., Gumus, S., Kucukvar, M., \& Tatari, O. (2016). A fuzzy data envelopment analysis framework for dealing with uncertainty impacts of input-output life cycle assessment models on eco-efficiency assessment. Journal of Cleaner Production, 129, 622-636. https://doi.org/10.1016/j.jclepro.2016.03.111

Fouladgar, M. M., Yazdani-Chamzini, A., Lashgari, A., Zavadskas, E. K., \& Turskis, Z. (2012). Maintenance strategy selection using AHP and COPRAS under fuzzy environment. International Journal of Strategic Property Management, 16(1), 85-104. https://doi.org/10.3846/1648715X.2012.666657

Gan, Q., \& Hill, R. J. (2009). Measuring housing affordability: looking beyond the median. Journal of Housing Economics, 18(2), 115-125. https://doi.org/10.1016/j.jhe.2009.04.003

Gau, W. L., \& Buehrer, D. J. (1993). Vague sets. IEEE Transactions on Systems, Man, and Cybernetics, 23(2), 610-614.

https://doi.org/10.1109/21.229476

Gürbüz, T., Alptekin, S. E., \& Alptekin, G. I. (2012). A hybrid MCDM methodology for ERP selection problem with interacting criteria. Decision Support Systems, 54(1), 206-214. https://doi.org/10.1016/j.dss.2012.05.006

Hajek, P., \& Froelich, W. (2019). Integrating TOPSIS with interval-valued intuitionistic fuzzy cognitive maps for effective group decision making. Information Sciences, 485, 394-412. https://doi.org/10.1016/j.ins.2019.02.035

Hashemi, H., Bazargan, J., \& Mousavi, S. M. (2013). A compromise ratio method with an application to water resources 
management: an intuitionistic fuzzy set. Water Resources Management, 27, 2029-2051.

https://doi.org/10.1007/s11269-013-0271-X

Jia, F., Liu, Y., \& Wang, X. (2019). An extended MABAC method for multi-criteria group decision making based on intuitionistic fuzzy rough numbers. Expert Systems with Applications, 127, 241-255.

https://doi.org/10.1016/j.eswa.2019.03.016

Karsak, E. E., \& Dursun, M. (2015). An integrated fuzzy MCDM approach for supplier evaluation and selection. Computers \& Industrial Engineering, 82, 82-93.

https://doi.org/10.1016/j.cie.2015.01.019

Keshavarz Ghorabaee, M. K., Zavadskas, E. K., Amiri, M., \& Esmaeili, A. (2016). Multi-criteria evaluation of green suppliers using an extended WASPAS method with interval type-2 fuzzy sets. Journal of Cleaner Production, 137, 213-229. https://doi.org/10.1016/j.jclepro.2016.07.031

Mazher, K. M., Chan, A. P., Zahoor, H., Khan, M. I., \& Ameyaw, E. E. (2018). Fuzzy integral-based risk-assessment approach for public-private partnership IPs. Journal of Construction Engineering and Management, 144(12), 0401811. https://doi.org/10.1061/(ASCE)CO.1943-7862.0001573

Mishra, A. R., \& Rani, P. (2018). Interval-valued intuitionistic fuzzy WASPAS method: application in reservoir flood control management policy. Group Decision and Negotiation, 27(6), 1047-1078. https://doi.org/10.1007/s10726-018-9593-7

Mohagheghi, V., Mousavi, S. M., Antuchevičienė, J., \& Dorfeshan, Y. (2019). Sustainable infrastructure projects selection by a new group decision-making framework introducing MORAS method in an interval type 2 fuzzy environment. International Journal of Strategic Property Management, 23(6), 390-404. https://doi.org/10.3846/ijspm.2019.10536

Mulliner, E., Malys, N., \& Maliene, V. (2016). Comparative analysis of MCDM methods for the assessment of sustainable housing affordability. Omega, 59, 146-156. https://doi.org/10.1016/j.omega.2015.05.013

Navarro, I. J., Penadés-Plà, V., Martínez-Muñoz, D., Rempling, R., \& Yepes, V. (2020). Life cycle sustainability assessment for multi-criteria decision making in bridge design: a review. Journal of Civil Engineering and Management, 26(7), 690-704. https://doi.org/10.3846/jcem.2020.13599

Pamučar, D., \& Ćirović, G. (2015). The selection of transport and handling resources in logistics centers using Multi-Attributive Border Approximation area Comparison (MABAC). Expert Systems with Applications, 42(6), 3016-3028. https://doi.org/10.1016/j.eswa.2014.11.057

Pires, A. S., Ferreira, F. A., Jalali, M. S., \& Chang, H. C. (2018). Barriers to real estate investments for residential rental purposes: mapping out the problem. International Journal of Strategic Property Management, 22(3), 168-178.

https://doi.org/10.3846/ijspm.2018.1541

Ranganath, N., Sarkar, D., Patel, P., \& Patel, S. (2020). Application of fuzzy TOPSIS method for risk evaluation in development and implementation of solar park in India. International Journal of Construction Management, 1-11. https://doi.org/10.1080/15623599.2020.1826027

Roy, J., Ranjan, A., Debnath, A., \& Kar, S. (2016). An extended MABAC for multi-attribute decision making using trapezoidal interval type-2 fuzzy numbers. arXiv:1607.01254. https://arxiv.org/abs/1607.01254

Salimian, S., \& Mousavi, S. M. (2021). A healthcare assessment for recycling hazardous waste by a new intuitionistic fuzzy decision method based on an assembled proportionate eval- uation approach. Advances in Industrial Engineering, 55(3), 267-284. https://doi.org/10.22059/AIE.2021.328790.1798

Stević, Ž., Pamučar, D., Puška, A., \& Chatterjee, P. (2020). Sustainable supplier selection in healthcare industries using a new MCDM method: Measurement of alternatives and ranking according to COmpromise solution (MARCOS). Computers \& Industrial Engineering, 140, 106231.

https://doi.org/10.1016/j.cie.2019.106231

Stević, Ž., Pamučar, D., Subotić, M., Antuchevičiene, J., \& Zavadskas, E. K. (2018). The location selection for roundabout construction using Rough BWM-Rough WASPAS approach based on a new Rough Hamy aggregator. Sustainability, 10(8), 2817. https://doi.org/10.3390/su10082817

Su, L., \& Li, H. (2021). Project procurement method decisionmaking with spearman rank correlation coefficient under uncertainty circumstances. International Journal of Decision Support System Technology (IJDSST), 13(2), 16-44. https://doi.org/10.4018/IJDSST.2021040102

Taillandier, F., Taillandier, P., Tepeli, E., Breysse, D., Mehdizadeh, R., \& Khartabil, F. (2015). A multi-agent model to manage risks in construction project (SMACC). Automation in Construction, 58, 1-18.

https://doi.org/10.1016/j.autcon.2015.06.005

Turskis, Z., Antuchevičienè, J., Keršulienè, V., \& Gaidukas, G. (2019). Hybrid group MCDM model to select the most effective alternative of the second runway of the airport. Symmetry, 11(6), 792. https://doi.org/10.3390/sym11060792

Turskis, Z., Zavadskas, E. K., Antucheviciene, J., \& Kosareva, N. (2015). A hybrid model based on fuzzy AHP and fuzzy WASPAS for construction site selection. International Journal of Computers Communications \& Control, 10(6), 113-128. https://doi.org/10.15837/ijccc.2015.6.2078

Wang, Y. J. (2015). Ranking triangle and trapezoidal fuzzy numbers based on the relative preference relation. Applied Mathematical Modelling, 39(2), 586-599. https://doi.org/10.1016/j.apm.2014.06.011

Wu, Y., Geng, S., Xu, H., \& Zhang, H. (2014). Study of decision framework of wind farm project plan selection under intuitionistic fuzzy set and fuzzy measure environment. Energy Conversion and Management, 87, 274-284. https://doi.org/10.1016/j.enconman.2014.07.001

$\mathrm{Xu}, \mathrm{Z}$. S., \& Chen, J. (2007). Approach to group decision making based on interval-valued intuitionistic judgment matrices. Systems Engineering - Theory \& Practice, 27(4), 126-133. https://doi.org/10.1016/S1874-8651(08)60026-5

Xue, Y. X., You, J. X., Lai, X. D., \& Liu, H. C. (2016a). An interval-valued intuitionistic fuzzy MABAC approach for material selection with incomplete weight information. Applied Soft Computing, 38, 703-713.

https://doi.org/10.1016/j.asoc.2015.10.010

Xue, Y. X., You, J. X., Zhao, X., \& Liu, H. C. (2016b). An integrated linguistic MCDM approach for robot evaluation and selection with incomplete weight information. International Journal of Production Research, 54(18), 5452-5467. https://doi.org/10.1080/00207543.2016.1146418

Yazdani, M., Alidoosti, A., \& Zavadskas, E. K. (2011). Risk analysis of critical infrastructures using fuzzy COPRAS. Economic Research-Ekonomska Istraživanja, 24(4), 27-40. https://doi.org/10.1080/1331677X.2011.11517478

Yue, Z. (2012). Extension of TOPSIS to determine weight of decision maker for group decision making problems with uncertain information. Expert Systems with Applications, 39(7), 6343-6350. https://doi.org/10.1016/j.eswa.2011.12.016 
Zavadskas, E. K., Antucheviciene, J., Razavi Hajiagha, S. H., \& Hashemi, S. S. (2014). Extension of weighted aggregated sum product assessment with interval-valued intuitionistic fuzzy numbers (WASPAS-IVIF). Applied Soft Computing, 24, 10131021. https://doi.org/10.1016/j.asoc.2014.08.031

Zavadskas, E. K., Kalibatas, D., \& Kalibatiene, D. (2016). A multi-attribute assessment using WASPAS for choosing an optimal indoor environment. Archives of Civil and Mechanical Engineering, 16(1), 76-85. https://doi.org/10.1016/j.acme.2015.10.002

Zavadskas, E. K., Turskis, Z., Antucheviciene, J., \& Zakarevicius, A. (2012). Optimization of weighted aggregated sum product assessment. Elektronika ir elektrotechnika, 122(6), 3-6. https://doi.org/10.5755/j01.eee.122.6.1810

Zavadskas, E., Baušys, R., \& Lazauskas, M. (2015). Sustainable assessment of alternative sites for the construction of a waste incineration plant by applying WASPAS method with singlevalued neutrosophic set. Sustainability, 7(12), 15923-15936. https://doi.org/10.3390/su71215792

Zhang, L., Zhao, Z., \& Kan, Z. (2019). Private-sector partner selection for public-private partnership projects of electric vehicle charging infrastructure. Energy Science \& Engineering, 7(5), 1469-1484. https://doi.org/10.1002/ese3.367 